\title{
Chapter 12 \\ Evaluating the Impacts of a New Railway \\ on Shorebirds: A Case Study in Central \\ Portugal (Aveiro Lagoon)
}

\author{
Tiago Múrias, David Gonçalves and Ricardo Jorge Lopes
}

\begin{abstract}
In 2007, the Portuguese Railway Company (REFER) began to build a new railway connecting the commercial port of Aveiro (Central Portugal) to the national rail network, which extended for about $9 \mathrm{~km}$ and crossed three of the remaining saltpans of the Aveiro Lagoon through a viaduct. Due to the importance of these habitats for shorebirds, and because the railway crossed a Natura 2000 site, the national biodiversity conservation authority required the impact assessment of this infrastructure. The study extended from 2006 (pre-construction), through 2008 and 2009 (construction), to 2011 (post-construction), encompassing four breeding and four wintering seasons. We used a Before-After-Control-Impact (BACI) design, with three impacted (those under the viaduct) and six control saltpans. During the breeding season (April-July) we monitored the numbers and breeding parameters of Black-winged stilt (Himantopus himantopus), and the numbers of Kentish plover (Charadrius alexandrinus) and Little tern (Sterna albifrons). In the winter, we monitored the numbers and spatial distribution of all shorebirds, and the activity of Dunlin (Calidris alpina). There was evidence for reductions in the abundance of the three breeding species in impacted saltpans in 2011, while no significant negative effects were found on abundances during 2008-2009 and on the breeding parameters of Black-winged Stilt. There was also evidence for reductions in wintering shorebird abundances in impacted saltpans in 2011, with no significant effects on abundances in 2008-2009, and on shorebird spatial distribution and activity patterns. Overall, the results suggest that the operation of a new railway close to important wetland habitats had negative impacts on the abundance of breeding and wintering shorebirds.
\end{abstract}

\footnotetext{
T. Múrias · D. Gonçalves · R.J. Lopes $(\varangle)$

CIBIO/InBIO, Centro de Investigação em Biodiversidade e Recursos Genéticos, Universidade do Porto, Campus Agrário de Vairão, Rua Padre Armando Quintas, 4485-661 Vairão, Portugal

e-mail: riclopes@me.com

D. Gonçalves

Departamento de Biologia, Faculdade de Ciências, Universidade do Porto,

Rua do Campo Alegre, 4169-007 Porto, Portugal

(C) The Author(s) 2017

L. Borda-de-Água et al. (eds.), Railway Ecology,

DOI 10.1007/978-3-319-57496-7_12
} 
Keywords Shorebirds · Wetlands - Saltpans • Impact • Railway

\section{Introduction}

The assessment of ecological effects on habitats and species of the construction and posterior operation of railways is still in its infancy when compared with other human-made infrastructures, like such as roads or powerlines, as largely stressed in Chap. 1. Although mortality is the most obvious and direct ecological effect of railways (as with other linear structures), the railways may also have indirect effects-namely as barriers for wildlife (Chap. 4), as vectors for the transport of alien species (Chap. 5), and as sources of disturbance (Chap. 6). In this book, most examples refer to railways on land or aquatic inland ecosystems (e.g. lakes, rivers), which is rather logical, since for the most part, railway lines are built overland. However, they may also impact non-terrestrial habitats (and associated species), when they are built in or near commercial ports. These are almost invariably located on estuaries, one of the most sensible ecosystems in terms of functioning and conservation, and critical for the conservation of many bird species (McLusky and Elliott 2004).

The eventual negative impacts of railways in estuarine systems may be particularly relevant for shorebirds and related species (Charadriiformes), which are among the birds of highest conservation concern (International Wader Study Group 2003; van de Kamp et al. 2004), due to their migratory status, feeding specialization, and, as a result, dependency on a limited set of areas for breeding, staging, and wintering (McLusky and Elliott 2004). Most of these species are very dependent on estuarine habitats and neighboring inland wetlands, as saltmarshes (Prater 1981) and, in southern Europe, also saltpans (Luís et al. 2002; Masero 2003; Múrias et al. 1997; Rufino et al. 1984). Therefore, it is important to assess the impacts of railways on this group of species, thereby allowing the development of adequate mitigation measures.

Portugal is one of the countries in southern Europe that holds international important wetlands for shorebirds, and where the development of railway networks to serve harbors can impact on estuarine and other coastal habitats. In these wetlands, saltpans appear to play an important role for shorebird conservation, as they are used both as refuges for sheltering at high tides, and as foraging habitats, especially when the mudflats are covered. Therefore, saltpans provide important sources of supplementary energy for birds, particularly during the demanding migratory periods and in winter (Dias et al. 2014; Lopes et al. 2005; Múrias et al. 2002; Rufino et al. 1984). Moreover, saltpans provide suitable breeding locations to populations of some shorebird species, such as Black-winged Stilt Himantopus himantopus, Kentish plover Charadrius alexandrinus, Redshank Tringa tetanus and Little tern Sterna albifrons (Fonseca et al. 2005; Jardim 1984; Múrias et al. 1997; Rufino and Araújo 1987). For the Black-winged stilt they even represent the most important breeding areas in Portugal (Rufino and Neves 1992).

Despite their importance for shorebirds, saltpans in Portugal are fast disappearing due to abandonment or conversion to aquaculture. As a result, only a few 
artisanal and industrial salt works still persist in the wetlands of Aveiro, Mondego, Tagus, and Sado estuaries, along the western coast of the country, as well as in wetlands along the southern coast of Algarve. According to figures from the most recent national census in 2015, there were only 73 saltpans in the whole country, which produced a total of 117 tons of salt (INE 2016). Once a thriving industry in the majority of the estuaries and coastal lagoons of the Portuguese coast, the marine salt extraction declined with the onset of new food conservation technologies and the reduction or abandonment of the once-prosperous long-range fishing fleet, particularly since the early 1960s (Rodrigues et al. 2011; Vieira and Bio 2014).

In this chapter, we provide a case study developed in the coastal lagoon of Aveiro (Ria de Aveiro), evaluating the response of shorebirds using saltpans to the impacts associated with the construction and operation of a new railway, both during the breeding and the wintering seasons. Under this scope, our specific objectives were to evaluate whether the railway affected (a) the numbers of the main breeding shorebirds (Black-winged Stilt, Kentish plover and Little tern); (b) the phenology and breeding success of Black-winged Stilt; and (c) the numbers, distribution, and activity of wintering shorebirds.

\section{Methodology}

\section{Study Area}

The study was carried out in Ria de Aveiro (Fig. 12.1), which is a complex lagoon system located in western Portugal at the mouth of the Vouga River that covers an area of approximately $450 \mathrm{~km}^{2}$. For centuries, marine salt extraction occupied a large part of this system (Bastos 2009; Rodrigues et al. 2011). By the early 1970s, there were still some 270 saltpans (1160 ha), but in subsequent decades, most of these saltpans were abandoned, flooded, and/or converted for other purposes (e.g., aquaculture production), with only nine saltpans (56 ha) persisting in 2007 (Bastos 2009; Rodrigues et al. 2011). In contrast, a busy trading and fishing harbor has grown in the last few decades, particularly since it was linked by a highway to the Spanish border. To connect the harbor to the national rail network, a new railroad connection about $9 \mathrm{~km}$ long started to be built in 2007 (REFER 2009). The engineering and environmental problems faced by the project were challenging, because this was a densely populated area, and Ria de Aveiro is a wetland included in the Natura 2000 network, established by the European Directive 92/43/EEC. Furthermore, the proposed rail path crossed important wetland areas, including eight of the last remaining untransformed saltpans, and there were no technically viable alternatives. For this reason, it was decided that the railway should cross the saltpans and adjoining areas through a $5.5 \mathrm{~km}$ viaduct, to minimize the loss of important shorebird habitats. Despite these efforts, three saltpans were directly affected by sustaining viaduct pillars (Fig. 12.1), or the construction of a service road (REFER 2009). 

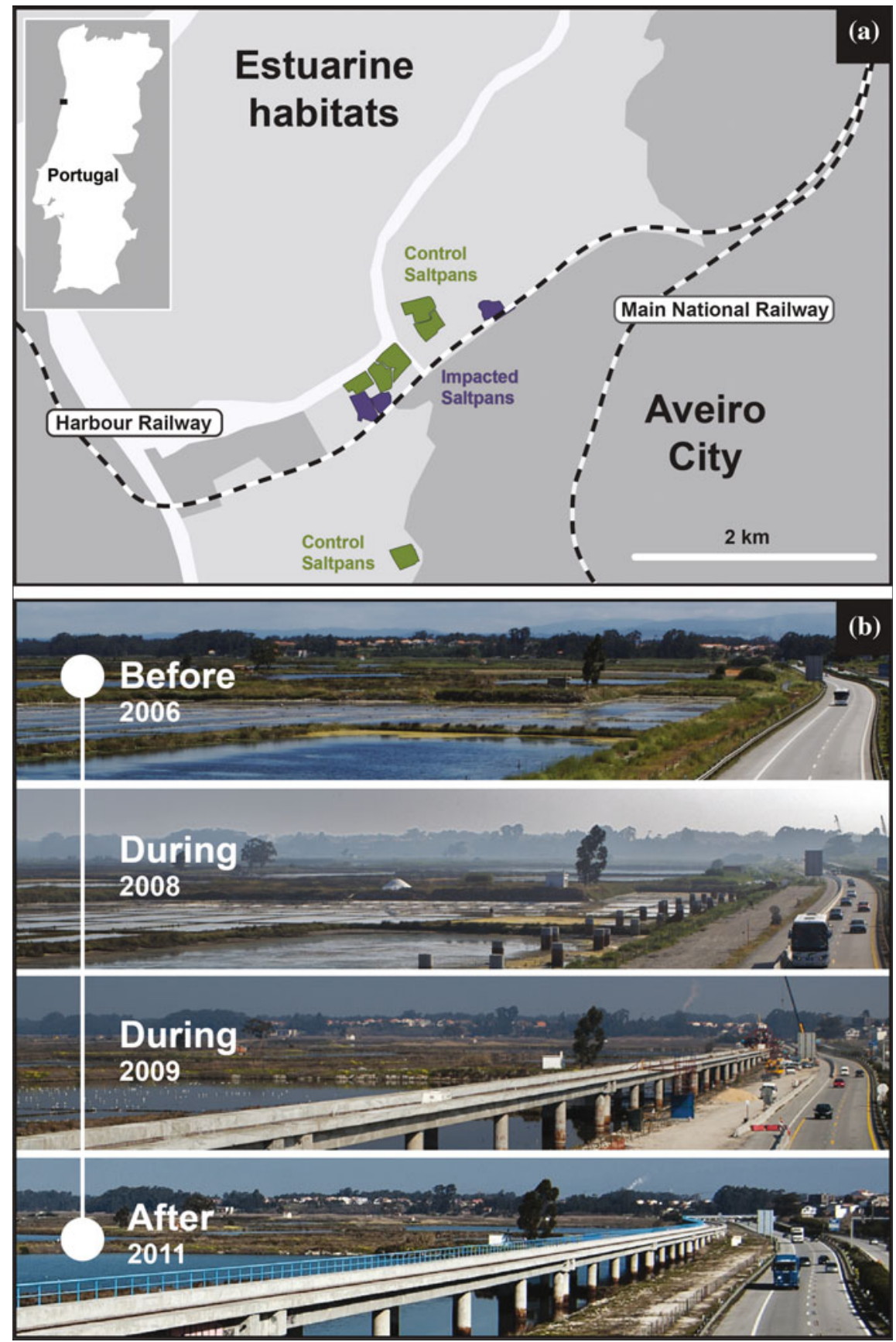

Fig. 12.1 a Map of the study area in Ria de Aveiro (Portugal), showing the location of the new railway line and the saltpans that were impacted by the construction and functioning of the railway (blue) and the saltpans that were used as control sampling units (green). b Timeline of the different phases, with photos of the same railway viaduct section, also showing one of the impacted saltpans 


\section{Study Design}

The study was based on a Before-After-Control-Impact (BACI) designed to test for the impacts of railway construction and operation in shorebirds using saltpans. Sampling was carried out on three time periods (Fig. 12.1) six years: one control year before the construction (2006); two years during the phase of construction (2008 and 2009); and one year in the post-construction (i.e., operation) phase (2011). Each "treatment" phase (i.e., construction and post-construction) was compared with the control phase (i.e., pre-construction) using as sampling units three impacted (those under the viaduct) and six control saltpans (Fig. 12.1). The presence of significant interactions between year and type of pond (i.e., control vs. impact) was understood to indicate significant railway impacts-either positive or negative-depending on the sign of the interaction term. We used saltpans as sampling units because they were the most important shorebird habitats affected by the project, and because they form discrete units where it is possible to make absolute counts both of all birds and their nests. Moreover, they have easy access and they were the only nesting areas used by shorebirds close to the railway corridor. Periodical winter counts in the surrounding saltmarshes did not reveal a substantial usage of these areas by shorebirds, with the exception of a small number of Dunlin (Calidris alpina) and common sandpiper (Actitis hypoleucos), which seemed to be largely insensitive to the construction of the pillars (personal observation).

We focused the impact assessment on breeding and wintering seasons, which are the two most critical periods in the phenology of shorebirds. During the breeding season (April-July), data were gathered from visits carried out at weekly intervals to all saltpans. During the winter season (January-February) we made regular, but interspersed visits (at least 1-week intervals) to all saltpans to obtain a suitable number of sampling occasions. In each sampling visit, selected parameters (see below) were estimated in all saltpans based on pre-established transects and observation points, by a team of two researchers using binoculars and telescopes. Detailed maps of bird distribution in each saltpan were produced at each visit.

Statistical analysis was carried out in the R 3.2.6 statistical environment (R Core Team 2015), using packages lmer4 (Bates et al. 2015), glmmADMB (Fournier et al. 2012), and lsmeans (Lenth 2016; Bates et al. 2015).

\section{Evaluating Effects on Breeding Shorebirds}

Shorebirds are mobile animals and can thus avoid potential impacts by moving away from impacted saltpans (Cayford 1993). When they remain in the impacted saltpans, however, they may still change their spatial distribution (individuals or nests), which may eventually affect their phenology or breeding success, through reduced nest or chick survival (Sansom et al. 2016; Pearce-Higgins et al. 2007). We tested these ideas by focusing on the three main breeding shorebird species: 


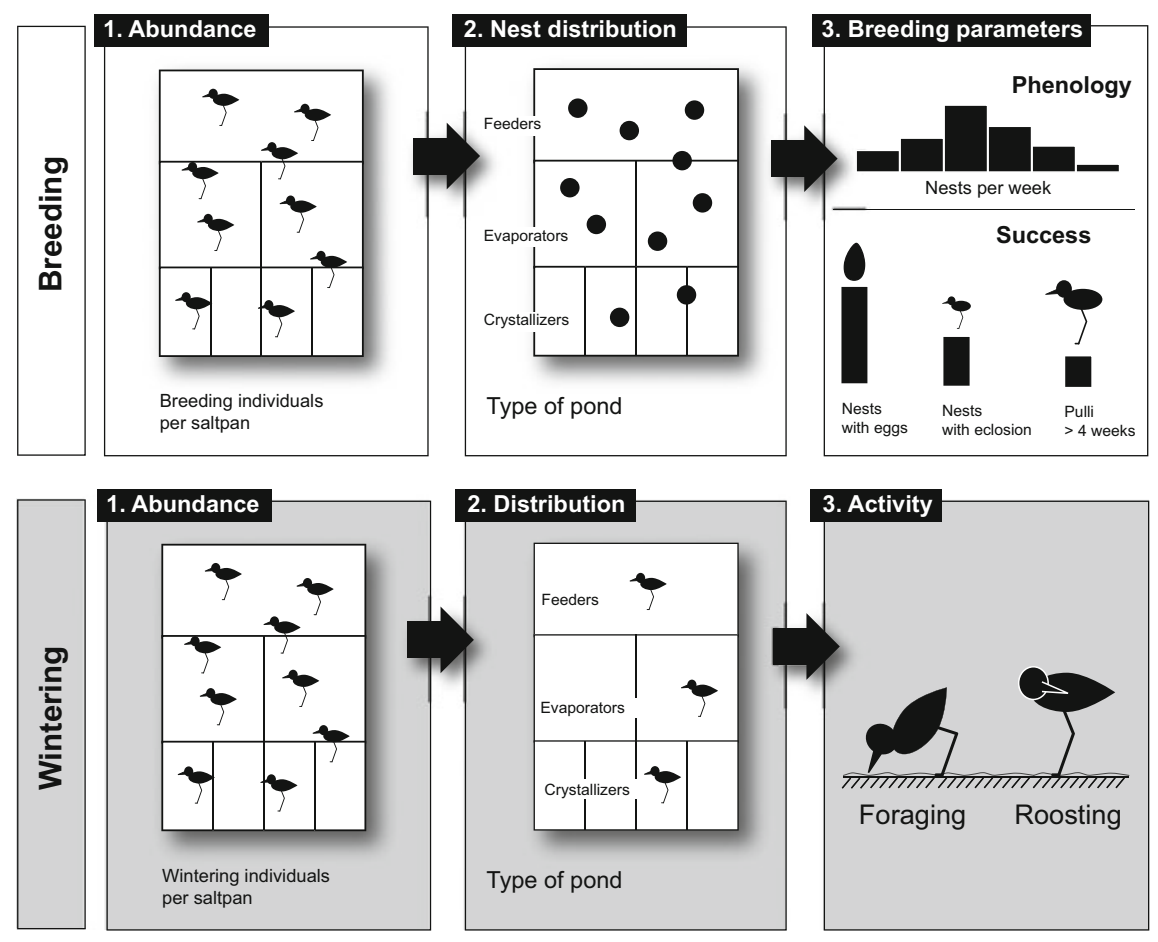

Fig. 12.2 Outline of the sampling rationale and parameters collected to test for the impacts of a new railway on shorebirds breeding and wintering in saltpans of Ria de Aveiro (Portugal)

Black-winged Stilt, Kentish plover, and Little tern. A more detailed study was made of the Black-winged Stilt, because it was the only species breeding on all saltpans in reasonable numbers, and it was the only one amenable to reliable surveys while minimizing disturbances, due to the relatively large size and conspicuousness of nests and chicks. Therefore, besides abundance, for this species we estimated for this species the distribution of nests, phenology and breeding success (Fig. 12.2). Overall, we tested the following hypothesis:

1. The overall abundance of each breeding species should decrease in the impacted saltpans.

2. The distribution of Black-winged Stilt nests should change within impacted saltpans.

3. For the Black-winged Stilt, the (a) nesting phenology should be delayed, and (b) breeding success should be lower in impacted saltpans in comparison to control saltpans. 


\section{Breeding Shorebird Abundance}

For the three focal species, we recorded the number of individuals per saltpan on a weekly basis during the breeding season. We tested for the effects of time (year) and type of saltpan (impacted vs. control) on the weekly number of individuals using GLMM with negative binomial distribution, controlling for overdispersion (Crawley 2013). The saltpan and the week of census were used as random factors. An offset variable was always specified to account for variation in the area (hectares) of the saltpans. The models' fitness was assessed graphically (residuals inspection), and they were compared with null models to test their significance (Zuur et al. 2009).

\section{Spatial Distribution of Black-Winged Stilt Nests}

Each saltpan was divided into three pond categories (feeders, evaporators, and crystallizers), according to their position, size, and microhabitat characteristics, such as water level (Rodrigues et al. 2011). Black-winged stilt nests are not distributed randomly among these categories (Tavares et al. 2008), and we expected that the disturbance caused by the construction and operation of the railway would affect the distribution of nests. For this reason, we recorded the spatial distribution of all Black-winged stilt nests according to type of pond. We then tested for differences in the number of nests and the type of pond, time of year, and type of saltpan (impacted vs. control) using a GLMM with a negative binomial distribution, controlling for overdispersion and saltpan area (Crawley 2013), and specifying the saltpan and week of visit as random factors.

\section{Black-Winged Stilt Nest Phenology and Breeding Success}

Black-winged stilts incubate 3-4 eggs for 4 weeks, and chicks remain in the same saltpan while not yet able to fly and are protected by their parents. Five weeks after hatching, chicks are no longer restricted to the saltpan where they were born, because they can already fly and follow their parents (del Hoyo et al. 1996). We recorded the timing of deployment of nests during the breeding season on a weekly basis (see above) in all saltpans (impacted and control). We tested for differences in the temporal distribution of the nests with time of year and type of saltpan (impacted vs. control), using Kolmogorov-Smirnov tests (Griffin 1999) with the ks.test procedure (R Core Team 2015). Following nest identification (see above) we recorded, on a weekly basis, the number of chicks and their ages. This allowed estimation of two binomial parameters of breeding success: nest and fledgling success. A nest was considered successful if at least one chick up to one week old was observed, while fledging success was considered for each clutch when at least one chick reached the age of fledging (4-5 weeks). We tested for differences with time of year and saltpan (impacted vs. control) on nest and fledging success, using 
GLMM with a binary distribution function, and controlling for saltpan area (Crawley 2013). The saltpan identity was specified as a random factor.

\section{Evaluating Effects on Wintering Shorebirds}

As in the breeding season, wintering shorebirds can avoid potential impacts by moving away from impacted saltpans (Cayford 1993). If they stay, they may change their spatial distribution on impacted saltpans and their activity patterns, which may eventually affect their winter survival, mainly by affecting energy intake (Yasué et al. 2008; Robinson and Pollitt 2002). We monitored the number of all wintering shorebirds, and assessed their distribution and patterns of activity (Fig. 12.2), thereby testing the following hypothesis:

1. Shorebird abundance should decline in impacted saltpans in comparison to control saltpans.

2. The distribution of shorebirds within impacted saltpans should change after the beginning of the construction and operation of the railway.

3. The distribution and activity of shorebirds within impacted saltpans should change after the beginning of the construction and operation of the railway.

\section{Wintering Shorebird Abundance}

We estimated the number of individuals of all shorebird species in the saltpans, from counts carried out at regular intervals during the months of January and/or February (3-5 sampling occasions). Given the small number of counts per species and the associated overdispersion, we pooled the counts of all species. We tested for differences in the total number of shorebirds with time of year and type of saltpan (impacted vs. control), using a GLMM with a negative binomial distribution, controlling for overdispersion and using the saltpan area as an offset (Crawley 2013). Saltpan identity and survey week were specified as random variables.

\section{Shorebird Spatial Distribution and Activity Within Saltpans}

Using the same rationale established for the breeding season, we recorded the spatial distribution of shorebirds in each saltpan according to the type of pond (feeders, evaporators, and crystallizers). We then tested for variation in the total number of shorebirds in relation to the type of pond, time (year) and type of saltpan (impacted vs control) using a GLMM with a negative binomial distribution, controlling for over-dispersion and saltpan area (Crawley 2013). Saltpan identity and the survey week were specified as random variables.

We also recorded the activity (foraging vs roosting) of each shorebird. Because activity budgets differ between species, we used only for Dunlin data for this 
analysis, because this was the most abundant species. We tested for differences in activity with time (year) and type of saltpan (impacted and control) using a GLMM with a binomial distribution function, controlling for saltpan area (Crawley 2013).

\section{Results}

\section{Effects on Breeding Shorebirds}

\section{Shorebird Abundances}

The average abundance of breeding shorebirds presented large variations, which ranged from the complete absence in some saltpans, in a breeding season, to maximum average values per saltpan of 36.2 Black-winged stilts ( 9.3 birds/ha), 26.0 Kentish plovers (7.9 birds/ha) and 89.7 Little terns (23.0 birds/ha) in 2006. For the three focal species, there was a significant interaction term between time and type of pond (Table 12.1), thus pointing out an impact of the construction and operation of the railway viaduct. Regarding the construction phase, there were significant increases in the abundance of Kentish plover (2008) and Little tern (2008 and 2009) in impacted saltpans in relation to the expectation from temporal trends at control saltpans (Table 12.1). However, during the operation phase (2011), the numbers of Black-winged Stilt, Kentish plover, and Little tern declined in impacted saltpans in relation to the expectation from temporal trends at control saltpans (Table 12.1).

\section{Black-Winged Stilt Nest Spatial Distribution Within the Saltpans}

The total number of nests at the saltpans monitored showed a steady negative temporal trend: annual average $=81.2($ density=22.3 nests $/$ ha $), 2006=97(26.6$ nests/ha), $2008=89$ (22.6 nests/ha), $2009=81$ (21.1 nests/ha), $2011=58$ (17.5 nests/ha). Considering the four years, it was found that most of the Black-winged Stilt nests were built in feeders (annual average $=32.2$ nests) and evaporators (45.7 nests), while few were found in crystallizers ( 3.2 nests). There was no evidence of the railway affecting nest numbers, as the full GLMM did not differ significantly from the model without the interaction term (Table 12.1).

\section{Black-Winged Stilt Breeding Phenology and Success}

Overall, the nesting phenology of Black-winged stilts was clearly unimodal, with the first nest detected in week 16 (late April) and the last on week 27 (early July), with a peak number of nests in week 21 (end of May) (Fig. 12.3). There were no significant differences in phenology between impacted and control in any phase, but 


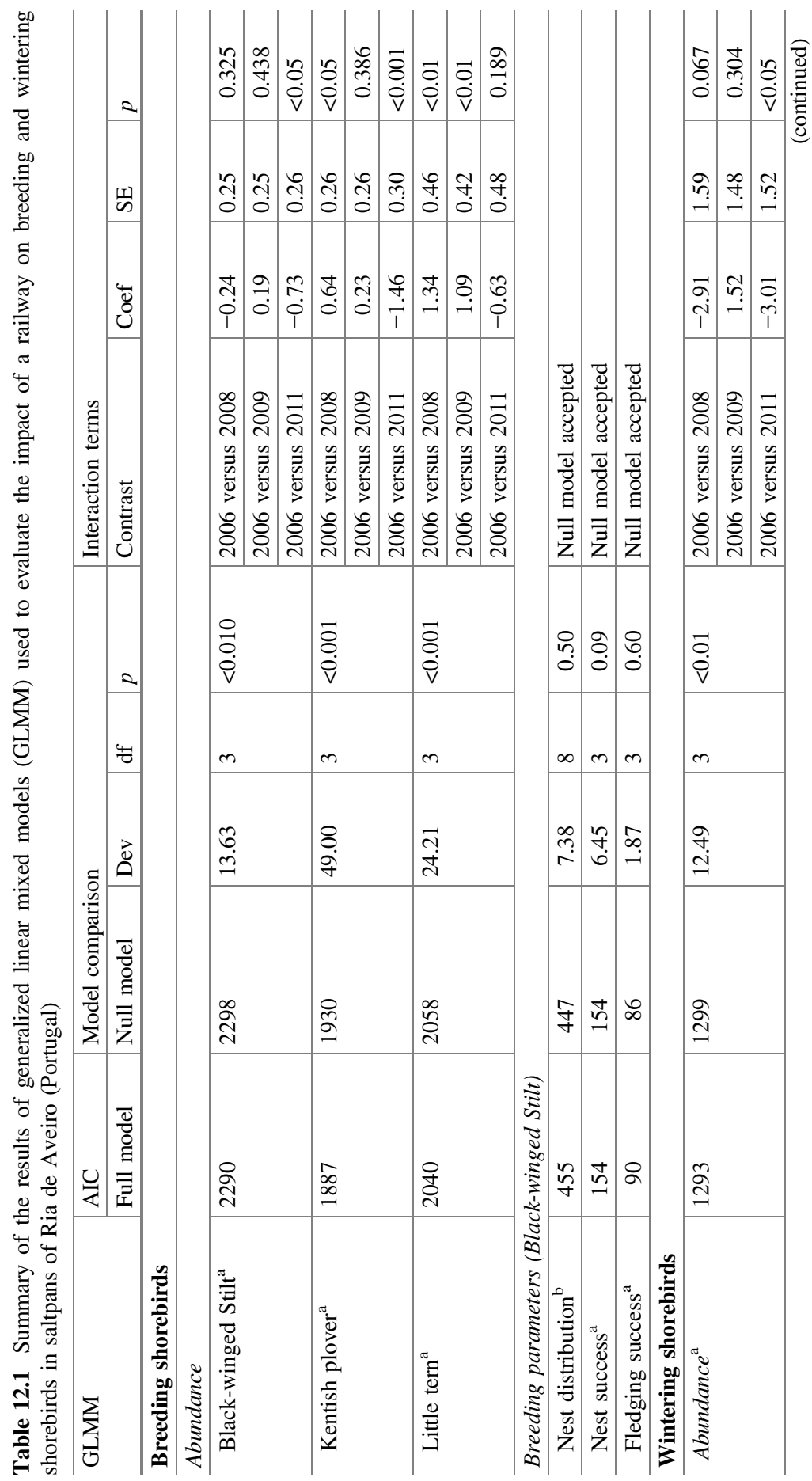




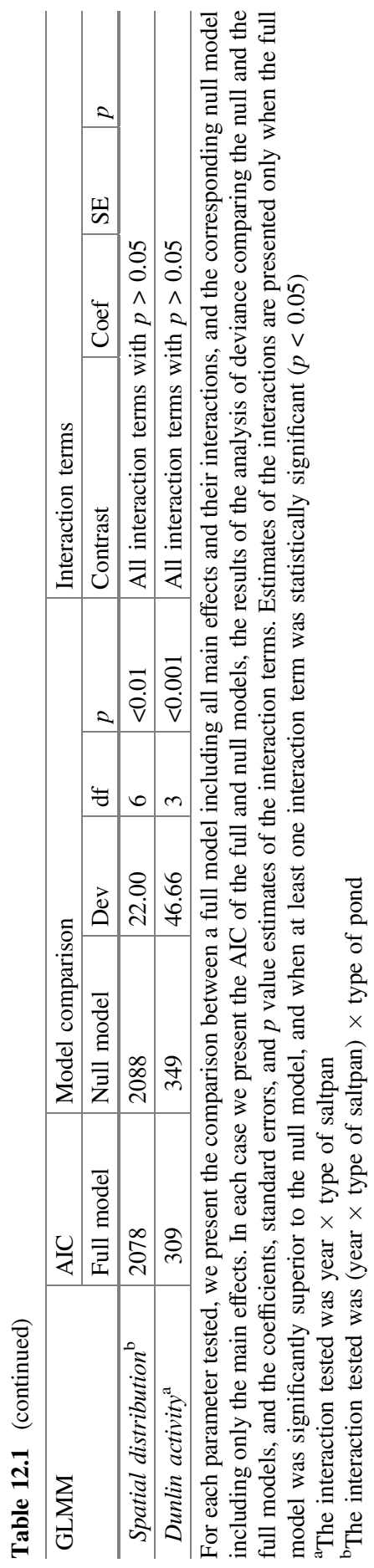




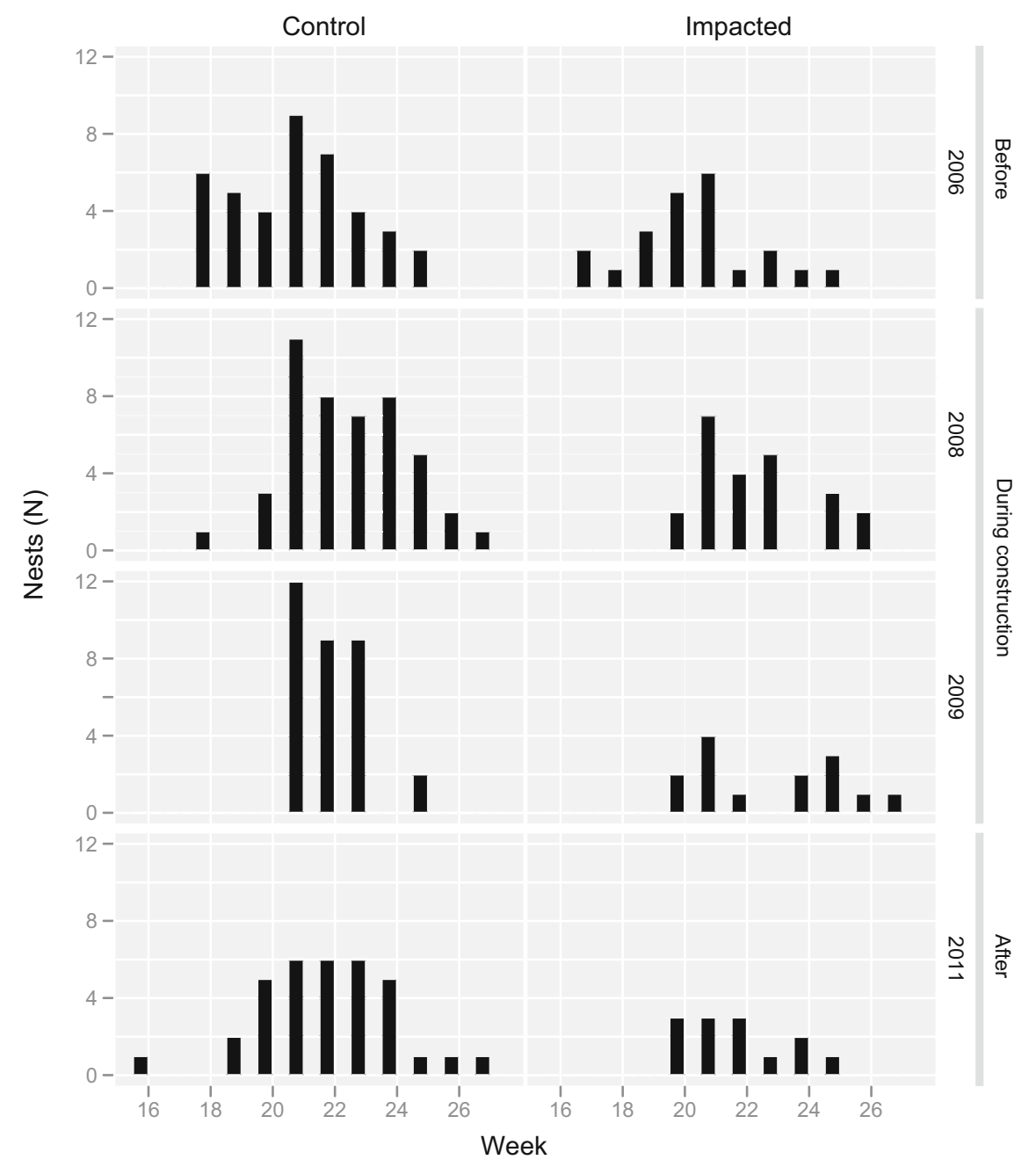

Fig. 12.3 Number of nests per week of Black-winged Stilt in impacted and control saltpans of Ria de Aveiro (Portugal), before (2006), during (2008-2009), and after (2011) the construction of a new railway in the study area

there were differences between the control and construction phases in impacted $(\mathrm{D}=0.39, p<0.05)$ and control $(\mathrm{D}=0.32, p<0.01)$ saltpans, with fewer early nests and more late season nests in the latter. We did not find significant differences in temporal nest distribution between the construction and the post-construction phase in either impacted $(\mathrm{D}=0.19, p=0.86)$ or control saltpans $(\mathrm{D}=0.18$, $p=0.40$ ). This suggests an overall delay in nesting phenology, irrespective of proximity to the railway. 


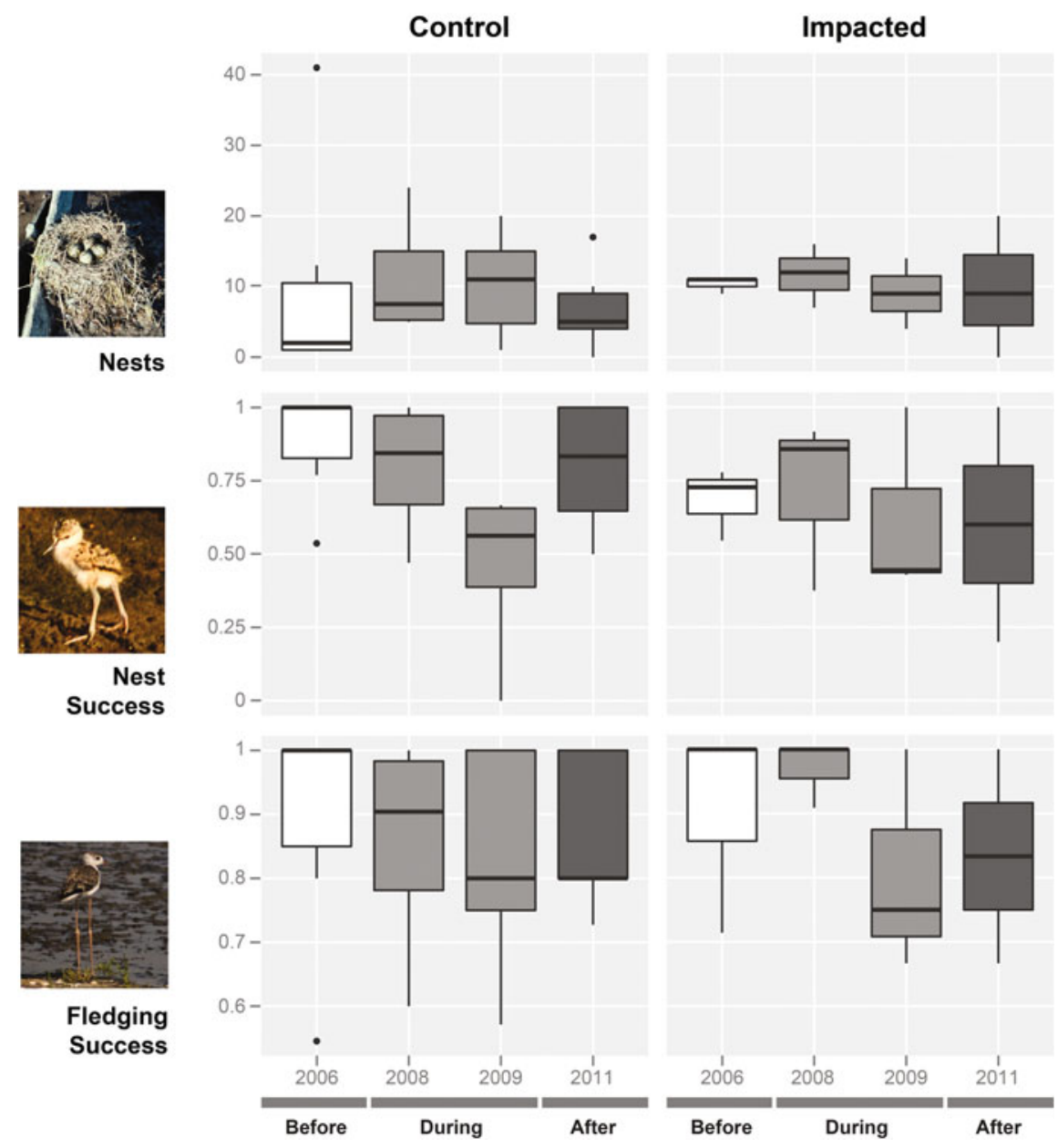

Fig. 12.4 Boxplots showing variation in the number of Black-winged Stilt nests, and nest and fledging success, in impacted and control saltpans of Ria de Aveiro (Portugal), before (2006), during (2008-2009), and after (2011) the construction of a new railway in the study area

The nest success (global $=62 \%, 2006=65 \%, 2008=68 \%, 2009=52 \%$, $2011=64 \%$ ) and fledging success (global $=52 \%, 2006=49 \%, 2008=62 \%$, $2009=42 \%, 2011=51 \%$ ) were fairly constant over time (Fig. 12.4). There was no evidence of impacts on breeding success, as the full GLMMs did not differ significantly from the corresponding null models without the interaction term (Table 12.1). 


\section{Effects on Wintering Shorebirds}

\section{Shorebird Abundances}

The total number of shorebirds counted per winter varied between 9331 (2008) and 2166 (2009). Dunlin was the most abundant species, followed by the Black-tailed Godwit Limosa limosa. The full GLMM was significantly different from the null model without the interaction term, thus pointing out the presence of impacts from the railway (Table 12.1). The number of birds counted in the impacted saltpans during the operation phase (2011) was significantly lower than expected given the temporal trends observed at the control saltpans (Table 12.1).

\section{Spatial Distribution and Activity Within Saltpans}

The use of a specific type of pond (feeders, evaporators and crystallisers) in winter did not show significant differences with type of saltpan (impacted or control). Although the full GLMM was significantly different from a null model (Table 12.1), none of the variables presented significant interactions between the type of pond and the combined interaction between time of year and the type of saltpan. Likewise, although the full GLMM for activity differed significantly from the corresponding null model without the interaction term, none of the interaction terms was statistically significant (Table 12.1). This suggests that shorebirds did not change significantly their spatial distribution and activity within impacted saltpans during the construction and operation phases.

\section{Discussion}

During the breeding season, we detected significantly negative impact of the railway on the average abundance of Black-winged Stilt and Kentish plover. But, during the construction phase, it is likely that the interruption of the construction during the breeding phase in the whole area of the railway viaduct corridor, imposed by legal authorities, was crucial to reduce the impact of the construction phase and in the case of the Kentish plover (2008) and the Little tern (2008 and 2009) this had a positive impact on the average abundance in impacted saltpans. However, our data does not discriminate between birds that failed to breed from breeding individuals. These birds can be present at different saltpans in different sampling dates, and this increased the dispersion of the data and could have masked to some extent the real pattern.

In the case of the Black-winged Stilt, assumed to be the key indicator species to assess the impact of disturbance caused by the railway, we did not find significant evidence for any impact on the spatial distribution of nests, breeding phenology and 
breeding success. The results suggest that the distribution of Black-winged Stilt between types of pond (feeders, evaporators and crystallizers) was not particularly affected by the construction. The major disturbance took place in the crystallizers, where the pillars were erected. However, as the results above show, these were the areas less used by the species, even in the pre-construction phase, which may be the reason why no impact was observed during the entire construction period and afterwards. Concerning nest phenology, the interruption of construction probably prevented an impact on the temporal distribution of nests. Likewise, this may explain why we did not find any evidence that the railway affected hatching and survival of the fledglings that used impacted saltpans.

During the wintering season, the usage of the saltpans can be conditioned by their availability, particularly by unpredictable fluctuations in the water level. Thus, the birds may be more limited in their choice of the saltpans, causing a high variability in the counts. This effect is more restricted during the breeding season due to the management of saltpans for the extraction of salt. During the last phase of this study, two saltpans (one impacted) were transformed into aquacultures, conditioning the use of the saltpans even more. Additionally, many of the shorebird species do not show a random distribution since they group for foraging or roosting, even if there is enough area to spread (van de Kamp et al. 2004). Even taking into account these sources of variability, the data suggest that the wintering community, as a whole, did show a negative response to the disturbance caused by the railway, since significant differences were found between the two types of saltpans over the years, regarding the species' abundance. Nevertheless, although the use of a pooled number of individual birds allowed the analysis of data that is inherently over-dispersed and zero-inflated, it restricts the full interpretation of the data. On the other hand, the distribution of the main wintering species was not affected, while for the wintering Dunlin, the number of birds in each activity did not show a response to the disturbance caused by the railway. Disturbances can inhibit foraging activities in favor of vigilant behaviour, but since all saltpans are close to sources of human disturbance (e.g., roads), the effect of the railway may have been buffered.

\section{Final Remarks}

As an overall conclusion, the data collected suggest that the construction and the beginning of the operation of the new Aveiro railway showed mixed effects on both the breeding and wintering communities of shorebirds using the Aveiro saltpan complex. Additionally, it had indirect effects, as it probably accelerated the abandonment of salt extraction in one of the affected saltpans, and thus promoted its transformation into an aquaculture during the last phase of our study. The net consequence of this process was the loss of this saltpan for the breeding birds, and also for feeding of the smaller shorebird species. At this point and with the present data, however, it is impossible to evaluate the consequences of this loss of habitat, 
and whether it could be compensated by the use of the other saltpans or other places outside the study area.

We applied an experimental design that provides a spatial and temporal context to integrate the evaluation of potential impacts of railways and other line infrastructures on wetlands. Our approach surpasses the usual estimators of mortality due to the effect of barrier and evaluates the effects on the spatial and temporal distribution, survival and behaviour. This decision was made due to the nature of this railway and the mitigation measures that were decided a priori to decrease the probability of negative impacts over the aquatic birds that uses the area crossed by this infrastructure. Indeed, the construction of a viaduct over the most critical areas was a decision that decreased land reclamation on the saltpans. On the other hand, this railway was meant from the start to be used for commercial purposes, transporting containers from the harbor to the main national line. The expected traffic and speed of the trains was thus limited and conditioned to specific daily periods, thus decreasing the barrier effect of this infrastructure and, hopefully, lowered the expected mortality due to collisions with the trains. In fact, during the study period, only two casualties were reported: a common Sandpiper (Actitis hypoleucos) and an unidentified gull.

The main guidelines described in this book pertaining to future studies in railway ecology seem mostly designed to terrestrial environments (and species) and long stretches of continuous railway beds. This study dealt (albeit in a preliminary way) with some of them, namely by (1) studying species with different ecological traits (even if belonging to the same taxonomic group), (2) using an experimental analysis, which includes comparison between a control phase with the period of construction and after, (3) studying the effect of habitat fragmentation (in this case, how the birds responded to the loss/degradation of the impacted saltpans both in the breeding season and in winter, and (4) a preliminary study of the population persistence in the area after the railway construction.

In our view, the most interesting feature of the present study is the integration of several spatial scales, from the macroscale of other case studies (see Chaps. 7 and 11) to the microscale of the habitat. This option was imposed by the nature of the problem itself and allowed us to go beyond the usual evaluation of mortality of adult birds due to collisions (Chap. 7) or the general patterns of disturbance and habitat loss (Chap. 11), and changed the focus of analysis to the impact of disturbance (both on the breeding and wintering birds) and chick mortality at smaller scales (habitat), a feature that is seldom attempted. We have developed a conceptual methodology where the rationale is hypothesis-based and uses a Before-After-Control-Impact comparative approach (as advised in the guidelines of Chap. 19). We think that it can be easily extended to the same or other aquatic bird species and habitats affected by railways in the wetland areas, enabling a multi-scale habitat analysis that can be combined with the usual broad scope procedures. Although the method has the potential to be improved and refined, we feel that it represents an add-on to the arsenal of methods of analysis in future studies of railway ecology, as those proposed in Chap. 19. 
Acknowledgements We would like to thank REFER (Rede Ferroviária Nacional E. P. E.), and especially Eng. João Sarmento for kindly making all data available for use in this publication. We also thank all the saltpan owners and workers for their support in the study area. Ricardo Jorge Lopes was supported by Grants SFRH/BPD/40786/2007 and SFRH/BPD/84141/2012, funded by FCT/MEC and POPH/QREN/FSE.

\section{References}

Bastos, M. R. (2009). On the track of salt: Adding value to the history of saltponds exploration in the coastal management scene of Aveiro lagoon. Journal of Integrated Coastal Zone Management, 9, 25-43.

Bates, D., Maechler, M., Bolker, B., \& Walker, S. (2015). Fitting linear mixed-effects models using lme4. Journal of Statistical Software, 67(1), 1-48.

Cayford, J. T. (1993). Wader disturbance: A theoretical overview. Wader Study Group Bulletin, $68,3-5$.

Crawley, M. J. (2013). The R book (2nd ed.). West Sussex, UK: Wiley.

del Hoyo, J., Elliott, A., \& Sargatal, J. (1996). Handbook of the birds of the world (Vol. 3) Hoatzin to Auks. Spain: Lynx Edicions, Barcelona

Dias, M. P., Lecoq, M., Moniz, F., \& Rabaça, J. E. (2014). Can human-made saltpans represent an alternative habitat for shorebirds? Implications for a predictable loss of estuarine sediment flats. Environmental Management, 53, 163-171.

Fonseca, V., Grande, N., \& Fonseca, L. C. (2005). Waterbird breeding on salinas in Ria Formosa, southern Portugal. Wader Study Group Bulletin, 106, 58-59.

Fournier, D. A., Skaug, H. J., Ancheta, J., Ianelli, J., Magnusson, A., Maunder, M. N., et al. (2012). AD model builder: Using automatic differentiation for statistical inference of highly parameterized complex nonlinear models. Optimization Methods and Software, 27(2), 233-249.

Griffin, L. R. (1999). Colonization patterns at Rook Corvus frugilegus colonies: Implications for survey strategies. Bird Study, 46, 170-173.

INE. (2016). Estatísticas da Pesca 2015. Lisboa: Instituto Nacional de Estatística.

International Wader Study Group. (2003). Waders are declining worldwide. Wader Study Group Bulletin, 101, 8-12.

Jardim, G. (1984). Recenseamento e distribuição de aves limícolas nidificantes no estuário do Tejo em 1983. Cyanopica, 3, 223-229.

Lenth, R. V. (2016). Least-squares means: The R package lsmeans. Journal of Statistical Software, 69(1), 1-33.

Lopes, R. J., Múrias, T., Cabral, J. C., \& Marques, J. C. (2005). A ten year study of variation, trends and seasonality of shorebird community in the Mondego Estuary. Portugal. Waterbids, 28(1), 8-18.

Luís, A., Moreira, H., \& Goss-Custard, J. (2002). The feeding strategy of the Dunlin (Calidris alpina L.) in artificial and non-artificial habitats at Ria de Aveiro, Portugal. Hydrobiologia, 475-476(1), 335-343.

Masero, J. A. (2003). Assessing alternative anthropogenic habitats for conserving waterbirds: Salinas as buffer areas against the impact of natural habitat loss for shorebirds. Biodiversity and Conservation, 12(6), 1157-1173.

McLusky, D. S., \& Elliott, M. (2004). The estuarine ecosystem. Oxford: Oxford University Press.

Múrias, T., Cabral, J. A., Lopes, R. J., Marques, J. C., \& Goss-Custard, J. D. (1997). Low-water use of the Mondego Estuary (West Portugal) by waders (Charadrii). Ardeola, 44(1), 79-91.

Múrias, T., Cabral, J. A., Lopes, R. J., Marques, J. C., \& Goss-Custard, J. D. (2002). Use of traditional salines by waders in the Mondego estuary (Portugal): A conservation perspective. Ardeola, 49, 223-240. 
Pearce-Higgins, J. W., Finney, S. K., \& Yalden, D. W. (2007). Testing the effects of recreational disturbance on two upland breeding waders. Ibis, 149(s1), 45-55.

Prater, A. J. (1981). Estuary birds of Britain and Ireland. Calton, UK: T \& A.D. Poyser.

$\mathrm{R}$ Core Team. (2015). R: A language and environment for statistical computing. Austria: $\mathrm{R}$ Foundation for Statistical Computing.

REFER. (2009). Ligação Ferroviária ao Porto de Aveiro. Rede Ferroviária Nacional E.P. (Direcção de Comunicação e Imagem), Lisboa, Portugal.

Robinson, J., \& Pollitt, M. S. (2002). Sources and extent of human disturbance to waterbirds in the UK: An analysis of Wetland Bird Survey data, 1995/96 to 1998/99. Bird Study, 49, 205-211.

Rodrigues, C., Bio, A., Amat, F., \& Vieira, N. (2011). Artisanal salt production in Aveiro/Portugal -An ecofriendly process. Saline Systems, 7(1), 3.

Rufino, R., \& Araújo, A. (1987). Seasonal variation in wader numbers and distribution at the Ria de Faro. Wader Study Group Bulletin, 51, 48-53.

Rufino, R., Araújo, A., Pina, J. P., \& Miranda, P. S. (1984). The use of salinas by waders in Algarve, South Portugal. Wader Study Group Bulletin, 42, 41-42.

Rufino, R., \& Neves, R. (1992). The effects on wader populations of the conversion of salinas into fishfarms. In M. Finlayson, T. Hollis, \& T. Davis (Eds.), Managing Mediterranean Wetlands and Their Birds: Proceedings of an IWRB International Symposium (pp. 177-182). Grado, Italy.

Sansom, A., Pearce-Higgins, J. W., \& Douglas, D. J. T. (2016). Negative impact of wind energy development on a breeding shorebird assessed with a BACI study design. Ibis, 158(3), 541-555.

Tavares, P., Kelly, A., Maia, R., Lopes, R. J., Serrão Santos, R., Pereira, M. E., et al. (2008). Variation in the mobilization of mercury into Black-winged Stilt Himantopus himantopus chicks in coastal saltpans, as revealed by stable isotopes. Estuarine, Coastal and Shelf Science, 77(1), 65-76.

van de Kamp, J., Bruno, E., Piersma, T., \& Zwarts, L. (2004). Shorebirds: An illustrated behavioural ecology. Utrecht, The Netherlands: KNNV Publishers.

Vieira, N., \& Bio, A. (2014). Artisanal salina-Unique wetland habitats worth preserving. Journal of Marine Science: Research \& Development, 4(1), e125.

Yasué, M., Dearden, P., \& Moore, A. (2008). An approach to assess the potential impacts of human disturbance on wintering tropical shorebirds. Oryx, 42(3), 415-423.

Zuur, A. F., Ieno, E. N., Walker, N., Saveliev, A. A., \& Smith, G. M. (2009). Mixed effects models and extensions in ecology with $R$. New York: Springer.

Open Access This chapter is licensed under the terms of the Creative Commons Attribution 4.0 International License (http://creativecommons.org/licenses/by/4.0/), which permits use, sharing, adaptation, distribution and reproduction in any medium or format, as long as you give appropriate credit to the original author(s) and the source, provide a link to the Creative Commons license and indicate if changes were made.

The images or other third party material in this chapter are included in the chapter's Creative Commons license, unless indicated otherwise in a credit line to the material. If material is not included in the chapter's Creative Commons license and your intended use is not permitted by statutory regulation or exceeds the permitted use, you will need to obtain permission directly from the copyright holder.

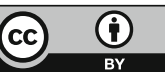

